Jordana Costa Soares ${ }^{1}$, Renata M. M. Carvallo ${ }^{2}$

\section{Reduction of Acoustic Reflex Threshold in Neonates without Auditory Risk}

Key words: acoustic reflex, newborns, auditory sensitization, facilitating stimulus.

\section{Summary}

\begin{abstract}
$\mathrm{T}$ he auditory sensitization, a tool used in the investigation of acoustic reflex, allows the decrease of acoustic reflex thresholds from a facilitating stimulus. It may be presented before or simultaneously with the elicitor tone. The thresholds after and before the facilitating stimulus are compared and it is expected to see the decreased threshold. From the study of the acoustic reflex it is possible to obtain information about the auditory pathways, such as structures of the brainstem, since the acoustic reflex pathway is related to the auditory nuclei in this site. They are also involved in auditory processing. Thus, alterations of the acoustic reflex could be related to deficits in auditory processing skills. Aim: This study aims at investigating the acoustic reflex sensitization from a highfrequency facilitating tone $(6 \mathrm{kHz})$ in newborns without risk factors to hearing impairment. Results: The acoustic reflex threshold decreased in males and females for all studied frequencies. Conclusion: A high-frequency facilitating tone presented simultaneously produced a decrease of the acoustic reflex threshold in newborns without risk factors to hearing impairment.
\end{abstract}




\section{INTRODUCTION}

The acoustic reflex involves the auditory nuclei in the brain stem related to auditory processing (Colletti et al., 1992'1 Carvallo, 19962). Therefore, acoustic reflex changes may suggest alterations on some auditory nuclei and impair skills related to hearing stimuli processing, such as location, selective attention, speech recognition amidst noise, and frequency selectivity (Carvallo, Albernaz, 1997) .

It is possible to assess the acoustic reflex thresholds of neonates and infants. Vincent, Gerber $(1987)^{4}$ found contralateral acoustic reflex on $92.5 \%$ of neonates with up to 48 hours of age and on $95 \%$ of infants with up to 6 weeks of age. McMillan et al. (1985) ${ }^{5}$ were also able to identify ipsilateral acoustic reflexes on $85-95 \%$ of the ears of 46 infants with ages ranging between 2 weeks and 12 months, all free from hearing alterations. Carvallo, Albernaz $(1997)^{3}$ identified ipsilateral acoustic reflex on $100 \%$ of infants included in their cases.

It is possible that there might be indirect multi-synaptic pathways involving other areas of the central nervous system aside from the acoustic reflex arc direct pathways. Borg $(1973)^{6}$ presented evidence of a pathway involving the reticular formation. The role of such pathway is yet unknown, but it may be related to complex characteristics of the acoustic reflex such as delivering anticipatory response, that is, to improve the acoustic reflex response (reducing the threshold) as observed in auditory sensitization procedures.

Acoustic reflex analysis -- as a possibility of investigating the efferent pathway -- depends on the integrity of the auditory afferent and efferent pathways. The auditory sensitization procedure has been used as a tool for acoustic reflex analysis, as it allows the acoustic reflex threshold reduction as of the introduction of a facilitating stimulus. Such stimulus may be introduced before or simultaneously to the tone used to elicit the acoustic reflex. Thresholds before and after exposure to the facilitating tone are compared. The one after exposure is expected to be lower, as reported by various authors.

Figure 1 (below) depicts one example of acoustic reflex sensitization. Initially, the reflex threshold at $2 \mathrm{kHz}$ was obtained at $84 \mathrm{~dB}$. When the threshold was assessed again, now with the introduction of a facilitating $6 \mathrm{kHz}$ tone in the intensity at which the acoustic reflex had been identified $(84 \mathrm{~dB})$, the threshold drops to $80 \mathrm{~dB}$.

Deutsch $(1973)^{7}$ studied auditory sensitization in adult patients with normal hearing and found reduced acoustic reflex thresholds in most subjects after stimulation by white noise. The author makes reference to the theory that considers the potential of enhancing VIII cranial nerve potential sensitivity by means of stimulation, and mentions the possibility of stimulation leading to fatigue and consequent recruitment (reduction on the acoustic reflex threshold). Sesterhen, Breuninger (1976) ${ }^{8}$ also found reduced acoustic reflex thresholds $(30 \mathrm{~dB})$ after the introduction of an $8 \mathrm{kHz}$ tone concurrently to the second assessment of the acoustic reflex thresholds on 25 adult ears. On a later study $(1977)^{9}$, the same authors found reduced acoustic reflex thresholds (20-30 dB) in normal ears and in ears with hearing loss after introducing concurrent 6 or $8 \mathrm{kHz}$ facilitating tones of the same intensity as that of the tone used to elicit the acoustic reflex. Blood, Greenberg $(1981)^{10}$ also identified reduced acoustic reflex thresholds when simultaneously introducing a facilitating tone in a single ear and in both ears.

Stelmachowicz, Gorga $(1983)^{11}$ concluded that the acoustic reflex threshold reduction does not depend on the frequency of the facilitating stimulus. They were able to observe threshold reductions at various frequencies $(500$ $\mathrm{Hz}, 1,2,4$ and $6 \mathrm{kHz}$ ), suggesting that the cochlea tonotopic pattern does not interfere in the process. The detected independence from frequency indicates that acoustic reflex facilitation is not primarily mediated by afferent mechanisms. The authors propose that facilitation takes place at the efferent portion of the acoustic reflex arc.

Jeck et al. (1983) ${ }^{12}$ have also observed reduced acoustic reflex thresholds of 10 to $12 \mathrm{~dB}$ in adults for frequencies of $500 \mathrm{~Hz}, 1$ and $2 \mathrm{kHz}$ using a $6 \mathrm{kHz}$ simultaneous facilitating tone. The authors suggested that sensitization may improve the signal-noise ratio in complex hearing scenarios by attenuating the lower frequencies.

Differently from other authors, Kumar and Barman $(2002)^{13}$ used broad band noise to find increased acoustic reflex thresholds. They introduced contralateral white noise simultaneously to the acoustic reflex threshold assessment. Thresholds were increased by $4 \mathrm{dBNA}$ at $1 \mathrm{kHz}$ and by 3.6 dBNA at $2 \mathrm{kHz}$. Such effect was imputed to the auditory

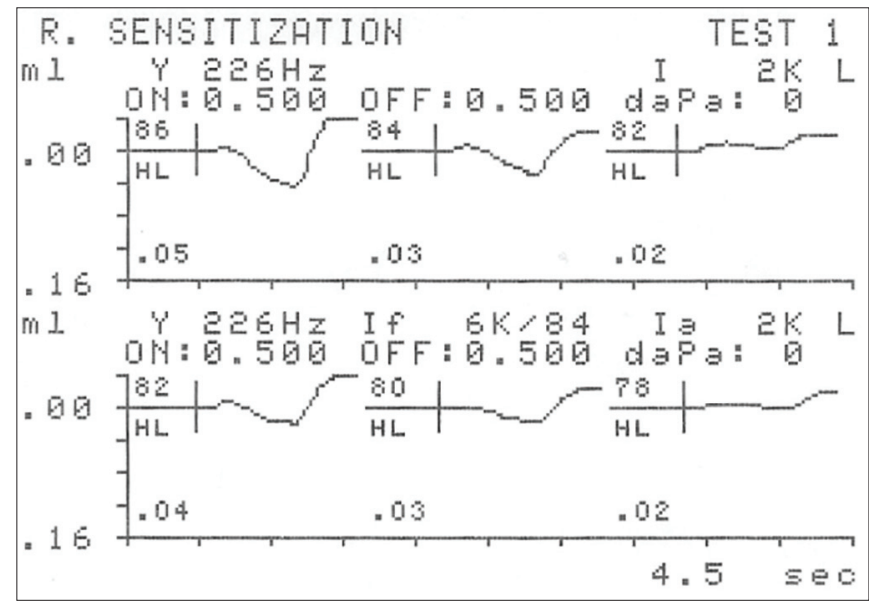

Figure 1. Example of the effect a $6 \mathrm{kHz}$ facilitating tone has on reducing the acoustic reflex threshold. 
efferent pathway activation by broad band noise.

Carvallo, Soares (2004) ${ }^{14}$ looked into acoustic reflex sensitization in young women without audiologic complaints and with tonal hearing thresholds within normal ranges. The frequencies analyzed were of $500 \mathrm{~Hz}, 1,2$ and $4 \mathrm{kHz}$ respectively, while the facilitating tone was of $6 \mathrm{kHz}$, introduced simultaneously and ipsilaterally. Acoustic reflex thresholds decreased in 6.7 to $13 \mathrm{dBNA}$ on right ears and in 14.3 to $17.2 \mathrm{dBNA}$ on left ears. The observed difference between the values found for right and left ears was not significant for any of the frequencies.

Studies analyzing the activation of the auditory efferent pathway have contributed to enhance the understanding of acoustic reflex reduction in adults. However, its occurrence in neonates still remains doubtful, as it has not been described in papers studying such population. Functional studies of the efferent pathway in neonates using other principles such as the analysis of suppressed otoacoustic emissions (Durante, Carvallo; 2002 ${ }^{15}$; During; $2004^{16}$ ) have shown that the efferent pathway is present at birth. Therefore it is reasonable to assume that acoustic reflex threshold reduction may also be found in neonates.

\section{OBJECTIVE}

This paper aims at investigating acoustic reflex threshold variations resulting from simultaneous ipsilateral application of a $6 \mathrm{kHz}$ facilitating stimulus in full term birth neonates, without indicated risk for hearing loss and with transient-evoked otoacoustic emissions.

\section{MATERIALS AND METHOD}

\section{Sample}

The sample comprised 40 full term babies, at proper weight for their ages, without prenatal, perinatal, or postnatal complication, and without indicated risk for hearing loss. Twenty babies of each gender were chosen for the study. Tests were carried out within the neonatal period.

The neonates participating in the study -- all under Informed Consent signed by their parents (research approved by the Ethics Committee of the USP University Hospital permit \# 174/01) - fit the following inclusion criteria:

1) Presence of TOAE on both ears during hearing screening, according to the criteria set by Brass, Kemp (1994)17, and Letourneau et al. (2000) ${ }^{18}$.

2) Ears with normal tympanometric curves, types A or $\mathrm{D}$ (double peak for neonates) and presence of acoustic reflex on at least two frequencies, so that the threshold comparison without and with $6 \mathrm{kHz}$ tone stimulation could be done.

\section{Materials}

- "ILO 292 / ECHOPORT PLUS Otodynamics Analyser" - for the acquisition of OAEs using the "Quickscreener' software, indicated for neonatal hearing screening. This software consists of a standard non-linear mode composed of four stimuli, three of which are equal to one another while the remaining one is reversed and three times greater in terms of amplitude. Response analysis time was of $12 \mathrm{~ms}$. Stimuli were of the 'click' type, had a duration of 80us and intensity of $80 \mathrm{~dB}$ at peak NPS equivalent (Otodynamics, 1992) ${ }^{19}$.

- Portable computer with a Pentium III processor, color monitor, with ILO V5 292 Echoport Plus Otodynamics Analyser installed.

- Grason Stadler TympStar Middle Ear Analizer release 2 immittancemeter - microprocessed and equipped with three tone frequencies probe: 226, 678 and $1000 \mathrm{~Hz}$. Tympanometric measures were carried out automatically by the device at 50 decaPascals per second $(\mathrm{daPa} / \mathrm{s})$. Results were plotted in a graph and printed out. The analysis of ipsilateral acoustic reflexes was done with stimuli calibrated in dBHL, played on a loudspeaker assigned exclusively to the ipsilateral mode. The signal was digitally multiplexed, thus allowing the probe tone (226 $\mathrm{Hz}$ ) to be separated from that of the stimulus avoiding overlapping waves and consequent generation of artifact. The equipment used to analyze ipsilateral acoustic reflex delivers a maximum output of $110 \mathrm{dBHL}$. It was calibrated for São Paulo city altitude, and all measures were taken from the standpoint of electrical installation so as to meet the manufacturer's technical specifications. (Grason-Stadler, 2001) $)^{20}$

\section{Procedures}

The procedures were carried out at the audiology department of the University Hospital of the University of São Paulo, in a quiet environment. The prenatal and neonatal health data and family information in regards to hearing and language skills were obtained by means of interviews with the mothers. Additional data on the prenatal and perinatal periods was collected from the hospital admission charts.

In order for procedures to be carried out, the neonates were at all times held by their mothers, preferably while asleep. Hearing screening - from the acquisition of TOAEs - was done using the 'Quickscreener' software, a tool developed specifically for that purpose. The probe, with a rubber tip in its tip, was fit to the external acoustic meatus to acquire the emissions in the first tested ear. The test began only after satisfactory conditions for the stabilization of the stimulus were achieved. Immittance measurements were carried out as subjects passed the criteria set for Hearing Screening of both ears. 
Immittance assessment was done starting by the right ear for one half of the subjects in the sample and by the left ear for the other half. Immittance screening comprised studies on tympanometric curve and acoustic reflex at $100 \mathrm{dBHL}$. The frequency of the tone produced by the immittance probe was of $226 \mathrm{~Hz}$. Neonates who did not present acoustic reflex in the screening mode at $100 \mathrm{dBHL}$ were sent to analysis in diagnostic mode.

After immittance screening, subjects underwent analysis of ipsilateral acoustic reflexes through the device special mode, where sensitization would be carried out further. The frequencies of the analyzed thresholds were 1,2 and $4 \mathrm{KHz}$, in $2 \mathrm{~dB}$ incremental steps. Tone length was $0.5 \mathrm{~s}$, with on time of $0.5 \mathrm{~s}$ and off time of $0.25 \mathrm{~s}$. Sensitization analysis was carried out separately for each of the frequencies mentioned previously after the first investigation of acoustic reflex threshold was completed.

The facilitating stimulus used was an ipsilateral $6 \mathrm{kHz} 0.5$ second long tone (length equal to that of the reflex-eliciting tone). For each frequency, the intensity of the facilitating stimulus was kept equal to that in which the acoustic reflex threshold had been obtained. The search for the new threshold was done in incremental steps of 2 $\mathrm{dB}$, with simultaneous exposure to the facilitating stimulus (6kHz).

One must bear in mind that the population analyzed by this study presents its inherent difficulties to being tested. Subjects were tested while asleep, and all procedures were carried out rapidly, as they could wake up at any moment. Many published papers report reductions in the acoustic reflex threshold by 10-12 dB (Jeck et al., 1983) and by 6-17 dB (Carvallo, Soares, 2004), to name a few. Thus, the second threshold analysis in this study was done at a frequency $10 \mathrm{~dB}$ below the first threshold obtained.

\section{RESULTS}

\section{Tympanometry (screening mode)}

In terms of tympanometric curves, for all 40 neonates, their two ears double peak curves (D) were present in $60 \%$ of the cases, while type A curves were found in the remaining $40 \%$. From the two proportions equality test, it was found that there is no significant difference between curve types ( $\mathrm{p}>0.05)$, as shown in Table 1 .

\section{Acoustic Reflex and Auditory Sensitization Analysis}

In regards to facilitating stimulus, the mean values for the acoustic reflex thresholds without (WO.FS) and with facilitating stimulus (W.FS) for males and females on each frequency for their right and left ears can be seen on tables 2 and 3 respectively. There was no significant difference between males and females, as in both Tables the $\mathrm{p}$ values were greater than $5 \%$.
Tables 4 and 5 show the mean values for the difference between thresholds obtained in the two scenarios of the study, i.e., without facilitating stimulus (W.FS) and with facilitating stimulus (W.FS). Although reduction is slightly higher among females in both ears, the difference is not statistically significant ( $p>0.05)$.

Table 1. Percentage of tympanometric curves present.

\begin{tabular}{lcccc}
\hline \multirow{2}{*}{ Tympanometric Curve } & \multicolumn{2}{c}{ RE } & \multicolumn{2}{c}{ LE } \\
\cline { 2 - 5 } & Qty & $\%$ & Qty & $\%$ \\
\hline Double Peak & 24 & $60 \%$ & 25 & $60 \%$ \\
A & 16 & $40 \%$ & 16 & $40 \%$ \\
Total & 40 & $100 \%$ & 40 & $100 \%$ \\
p-value & \multicolumn{2}{c}{0,074} & \multicolumn{2}{c}{0,074} \\
\hline
\end{tabular}

Table 2. Acoustic reflex thresholds without and with facilitating stimulus $-\mathrm{RE}$.

\begin{tabular}{llcccc}
\hline Right Ear & & Mean & STD & Size & $\begin{array}{c}\text { p- } \\
\text { value }\end{array}$ \\
\hline 1 KHz & Female & 96,43 & 10,62 & 14 & 0,621 \\
- WO.FS. & Male & 94,71 & 8,54 & 17 & \\
1 KHz & Female & 76,71 & 21,36 & 14 & 0,294 \\
- W.FS. & Male & 84,50 & 18,54 & 16 & \\
2 KHz & Female & 93,29 & 9,40 & 14 & 0,951 \\
- WO.FS. & Male & 93,06 & 10,59 & 17 & \\
2 KHz & Female & 72,29 & 23,94 & 14 & 0,196 \\
- W.FS. & Male & 81,47 & 11,77 & 15 & \\
4 KHz & Female & 91,85 & 7,77 & 13 & 0,914 \\
- WO.FS. & Male & 92,18 & 7,18 & 11 & \\
$4 \mathrm{KHz}$ & Female & 74,85 & 21,61 & 13 & 0,295 \\
- W.FS. & Male & 82,50 & 12,51 & 12 & \\
\hline
\end{tabular}

Table 3. Acoustic reflex thresholds without and with facilitating stimulus - LE.

\begin{tabular}{lllccc}
\hline Left Ear & & Mean & STD & Size & $\begin{array}{c}\mathrm{p}- \\
\text { value }\end{array}$ \\
\hline 1 KHz & Female & 92,67 & 9,00 & 15 & 0,643 \\
- WO.FS. & Male & 94,25 & 9,77 & 16 & \\
1 KHz & Female & 78,63 & 20,12 & 16 & 0,159 \\
- W.FS. & Male & 87,13 & 12,18 & 16 & \\
2 KHz & Female & 92,38 & 8,89 & 16 & 0,600 \\
- WO.FS. & Male & 94,13 & 9,76 & 16 & \\
2 KHz & Female & 75,87 & 21,15 & 15 & 0,155 \\
- W.FS. & Male & 85,20 & 12,78 & 15 & \\
4 KHz & Female & 91,67 & 8,86 & 12 & 0,219 \\
- WO.FS. & Male & 95,47 & 6,82 & 15 & \\
4 KHz & Female & 75,82 & 19,05 & 11 & 0,112 \\
- W.FS. & Male & 86,67 & 11,77 & 12 & \\
\hline
\end{tabular}


Table 4. Mean difference without and with facilitating stimulus - RE.

\begin{tabular}{lccccccc}
\hline \multirow{2}{*}{ Right Ear } & \multicolumn{2}{c}{$1 \mathrm{KHz}$} & \multicolumn{2}{c}{$2 \mathrm{KHz}$} & \multicolumn{2}{c}{$4 \mathrm{KHz}$} \\
\cline { 2 - 7 } & Female & & Male & Female & Male & Female & Male \\
\hline Mean & 19,71 & 9,88 & 21,00 & 10,40 & 20,08 & 11,40 \\
Standard Deviation & 21,16 & 13,85 & 23,05 & 7,49 & 16,71 & 10,11 \\
Size & 14 & & 16 & 14 & 15 & 12 & 0,167 \\
p-value & & 0,138 & & & 0,103 & & 10 \\
\hline
\end{tabular}

Table 5. Mean difference without and with facilitating stimulus - LE.

\begin{tabular}{|c|c|c|c|c|c|c|}
\hline \multirow[t]{2}{*}{ Left Ear } & \multicolumn{2}{|c|}{$1 \mathrm{KHz}$} & \multicolumn{2}{|c|}{$2 \mathrm{KHz}$} & \multicolumn{2}{|c|}{$4 \mathrm{KHz}$} \\
\hline & Female & Male & Female & Male & Female & Male \\
\hline Mean & 15,07 & 7,13 & 15,73 & 8,40 & 15,27 & 8,33 \\
\hline Standard Deviation & 16,95 & 7,27 & 16,65 & 7,49 & 13,84 & 11,81 \\
\hline Size & 15 & 16 & 15 & 15 & 11 & 12 \\
\hline$p$-value & \multicolumn{2}{|c|}{0,097} & \multicolumn{2}{|c|}{0,131} & \multicolumn{2}{|c|}{0,209} \\
\hline
\end{tabular}

\section{DISCUSSION}

Tympanometry screening underscored a distribution of results between two different configurations. Without analyzing them separately by gender, $60 \%$ of the right ear tympanometric curves presented double peak (type D) configuration, while $40 \%$ were type A. Both are deemed normal for the neonatal population. The same was found for left ears. Another paper (Vincent, Gerber, $1987)^{4}$ studying infants identified double peak tympanometric curves, which did not prevent the obtainment of acoustic reflexes.

It is important to stress that all subjects included in this study - both males and females - presented acoustic reflex thresholds in at least one of their ears when analyzed in the device off of the screening mode. The goal here was to verify sensitization by comparing thresholds without and with the $6 \mathrm{kHz}$ stimulus. That was possible only because all subjects presented acoustic reflexes.

The mean values found for acoustic reflex without facilitating stimulus ranged between 91 and 96 dBHL. Close values were also found by Carvallo, Albernaz $(1997)^{3}$ in their research on ipsilateral acoustic reflex in a population similar to that of this study. They used frequencies of 1 $\mathrm{kHz}$ and $2 \mathrm{kHz}$, and found values between $96.3 \mathrm{dBHL}$ at $1 \mathrm{kHz}$ and $95.2 \mathrm{dBHL}$ at $2 \mathrm{kHz}$. McMillan et al. (1985) also studied acoustic reflexes in infants at $500 \mathrm{~Hz}, 1$ and $2 \mathrm{kHz}$, finding mean threshold values between 80 and $85 \mathrm{dBHL}$.

The presentation of a facilitating stimuli brought significant reduction to acoustic reflex thresholds at all frequencies, for both ears of subjects from both genders, as seen in the literature ${ }^{10,12,14}$ of adult populations.

The facts observed in this study agree with various other papers ${ }^{10-12}$ insofar as frequency independence is concerned, as sensitization occurred in the neonatal population regardless of the frequency utilized. Further studies are required to determine whether or not the same would happen for other facilitating stimuli.

From what has been explained one might say that, apart from the conventional investigation of the stapedian reflex, it is also possible to assess the acoustic reflex threshold reduction (sensitization) in neonates. As authors agree that this occurrence is related to the auditory efferent pathway ${ }^{11}$, it may be used to assess this same pathway in neonates.

Additionally, the investigation on auditory sensitization in populations with dysfunctional efferent pathways and in individuals with altered auditory processing may be an important diagnostic tool. It will increase the certainty around the location in the auditory system where sensitization or acoustic reflex threshold reduction occurs, thus contributing to further scientific investigation on hearing.

\section{CONCLUSION}

Simultaneous exposure to high-frequency tones leads to reduced acoustic reflex thresholds, suggesting the effect the auditory efferent pathway may have, as early as in the neonatal stage, when activated by a simultaneous and high frequency stimulus. 


\section{REFERENCES}

1. Colletti V, Fiorino FG, Verlato MD, Carner M. Acoustic reflex in frequency selectivity: brain stem auditory evoked response and speech discrimination. In: Katz K, Stecher NA \& Henderson D. Eds. Central Auditory Processing: A Transdisciplinary View. St Louis Mosby Year Book; 1992.

2. Carvallo RMM. O efeito do reflexo estapediano no controle da passagem da informação sonora. In: Schochat E. (Org.) Processamento Auditivo. São Paulo: Editora Lovise; 1996. 57-73.

3. Carvallo RMM, Mangabeira Albernaz PL. Reflexos Acústicos em Lactentes. Acta AWHO 1997; 16 (3): 103-8.

4. Vincent VL, Gerber SE. Early development of the acoustic reflex audiology 1987; 26: 356-62.

5. Mcmillan PM, Marchant CD, Shurin PA. Ipsilateral acoustic reflexes in infants. Ann Otol Rhinol Laryngol 1985; 94: 145-8.

6. Borg E. On the neuronal organization of the acoustic middle ear reflex. A physiological and anatomical study brain research. 1973; 49: 101-23.

7. Deutsch LJ. Auditory sensitization in the human stapedius reflex. J Aud Res 1973; 13: 301-4.

8. Sesterhenn $G$, Breuninger $H$. The acoustic reflex at low sensation levels. Audiology 1976; 15: 523-33.

9. Sesterhenn G, Breuninger H. Determination of hearing threshold for single frequencies from the acoustic reflex. Audiology 1977; 16: 201-14.
10. Blood IM, Greenberg HJ. Low-level acoustic reflex thresholds. Audiology 1981; 20: 244-50.

11. Stelmachowicz PG, Gorga MP. Investigation of the frequency specificity of acoustic reflex facilitation. Audiology 1983; 22: 128-35.

12. Jeck LT, Ruth RA, Schoeny ZG. High-frequency sensitization of the acoustic reflex. Ear Hear 1983; 4(2): 96-101.

13. Kumar A, Barman A. Effect of efferent-induced changes on acoustical reflex. Int J Audiol 2002; 41: 144-7.

14. Carvallo RMM, Soares JC. Efeito do estímulo facilitador no limiar de reflexo acústico. Rev Bras Otorrinolaringol 2004; 70(2): 200-6.

15. Durante AS, Carvallo RMM. Contralateral suppression of otoacustic emissions in neonates. Int J Audiol 2002; 41: 211-5.

16. Durante AS. Supressão das emissões otoacústicas por transientes em neonatos com risco para alteração auditiva; 2004. 136f. Tese (Doutorado em Ciências) - Faculdade de Medicina, Universidade de São Paulo, São Paulo.

17. Brass D, Kemp DT. Quantitative assessment of methods for the detection of otoacustic emission. Ear Hear 1994; 15: 378-89.

18. Letourneau KS, Mcdermott C, Vohr BR. Factors affecting maternal anxiety in a universal screen program. In: Preliminary Program and Registration Book. Vol. 1. American Academy of Audiology, Annual Convention, Chicago: American Academy of Audiology 2000; 110.

19. Otodynamics LTD Ipsilateral and Contralateral TEOAE Suppression (for the ILO96 Research Level ILO92 \& Research Level ILO 292).

20. Grason-Stadler GSI TympStar Version 2 Middle-Ear Analyzer Reference Instruction Manual 2000-0120, Ver 20: October 2001. 